\title{
Agouti signalling protein is an inverse agonist to the wildtype and agonist to the melanic variant of the melanocortin- 1 receptor in the grey squirrel (Sciurus carolinensis)
}

Corresponding author:

Helen R. McRobie, Department of Life Sciences, Anglia Ruskin University, East Road, Cambridge CB1 1PT, UK, Telephone: +44 (0) 1223363271 extension 5083 email: helen.mcrobie@anglia.ac.uk

Co-authors:

Linda M. King, Anglia Ruskin University. email: $\underline{\text { linda.king@anglia.ac.uk }}$

Cristina Fanutti, University of East Anglia. email: c.fanutti@uea.ac.uk

Martyn F. Symmons, University of Cambridge. email: mfs1001@cam.ac.uk

Peter J. Coussons, Anglia Ruskin University. email: peter.coussons@anglia.ac.uk

\begin{abstract}
The melanocortin-1 receptor (MC1R) is a key regulator of mammalian pigmentation. Melanism in the grey squirrel is associated with an eight amino acid deletion in the $\mathrm{MC} 1 \mathrm{R} \Delta 24$ variant. We demonstrate that the $\mathrm{MC} 1 \mathrm{R} \Delta 24$ exhibits a higher basal activity than the wildtype MC1R (MC1R-wt). We demonstrate that agouti signalling protein (ASIP) is an inverse agonist to the MC1R-wt but is an agonist to the MC1R $\Delta 24$. We conclude that the eight amino acid deletion of the MC1R $\Delta 24$ leads to a constitutively active receptor which is further activated by ASIP. This is the first report of ASIP acting as an agonist to MC1R.
\end{abstract}

\section{Key words}

Melanocortin- 1 receptor, agouti signalling protein, melanocyte stimulating hormone, Sciurus carolinensis, grey squirrel, melanism 


\section{Abbreviations}

MC1R: melanocortin-1receptor

MC1R-wt: melanocortin-1 receptor of the wildtype

MC1R 24 : mutant melanocortin-1receptor with 24 base pair deletion

ASIP: agouti signalling protein

POMC: pro-opiomelanocortin

CREB: CAMP responsive element binding protein

TRP-1: tyrosinase-related protein

DCT: dopachrome tautomerase

$\alpha-\mathrm{MSH}$ : alpha melanocyte stimulating hormone

CAMP: cyclic adenosine monophosphate

TM: transmembrane helix

ECL: extracellular loop

\section{Introduction}

Animal pigmentation is often dramatic and strikingly beautiful and has many functions including thermoregulation, crypsis, protection and signalling. ${ }^{1,2,3,4,5,6,7}$

Colouration is determined by the type, amount and distribution of melanin pigments, which are produced in melanocytes found in hair follicles of the epidermis. Mammals produce two distinct melanins, phaeomelanin which is red/yellow and eumelanin which is brown/black. ${ }^{8}$ The protein products of the extension and agouti loci have been identified as key regulators in the production of these two pigments. The extension locus encodes the melanocortin-1 receptor (MC1R) and the agouti encodes the agouti signalling protein (ASIP). 
The MC1R is a seven transmembrane G protein-coupled receptor (GPCR) predominantly expressed in melanocytes. This receptor has a high basal level of ligand-independent constitutive activity; however the receptor is activated further by its agonist $\alpha$-melanocyte stimulating hormone ( $\alpha$-MSH). ${ }^{9,10,11} \alpha$-MSH is a small peptide secreted by the pituitary gland where it is cleaved from the precursor, proopiomelanocortin (POMC). $\alpha-\mathrm{MSH}$ is also produced by keratinocytes in the epidermis. ${ }^{12}$ Activation of the MC1R leads to raised intracellular levels of cAMP by coupling to adenylate cyclase activity. ${ }^{13,14}$ High cAMP levels lead to several signalling cascades including changes in gene expression via the cAMP responsive element binding protein (CREB) family of transcription factors. ${ }^{15}$ Intracellular cAMP levels are pivotal in determining the switch from eumelanin to phaeomelanin production. Basal levels of cAMP from unstimulated receptors are sufficient to stimulate the expression of the gene encoding tyrosinase which is the rate limiting enzyme required for the production of both eumelanin and phaeomelanin. ${ }^{16}$ Lower levels of cAMP reduce the expression of genes encoding tyrosinase-related protein 1 (TRP-1) and dopachrome tautomerase (DCT) which are required for eumelanogenesis but not phaeomelanogenesis. Raised cAMP levels have other effects on melanocytes including increased dendricity and increased proliferation with the overall effect of increased eumelanogenesis. ${ }^{17,18,19}$

ASIP is a 131 residue peptide produced by dermal papillae cells where it acts in a paracrine fashion on follicular melanocytes. In humans and mice, ASIP acts as a high affinity inverse agonist of the MC1R, inhibiting binding of the agonist $\alpha$-MSH and inactivating the receptor. ${ }^{20,21}$ Inactivation of the receptor leads to a fall in cAMP levels and a switch to phaeomelanogenesis and ultimately, cessation of pigment 
production. ${ }^{22,23}$ In this way ASIP acts with the MC1R to form a reversible switch determining which type of melanin is synthesised. Cyclical "off" and "on" switching of MC1R receptor by ASIP is needed to produce hairs with distinctive banding patterns found in wildtype agouti mice.

Wildtype agouti mice produce hairs which are black at the tips and base but contain a yellow subapical band. This band corresponds to a switch from eumelanin to phaeomelanin synthesis which is caused by a pulse of ASIP expression in the hair follicle during day four to six of the hair growth cycle. ${ }^{20}$ When this transient ASIP expression stops, eumelanogenesis resumes. The wildtype grey squirrel (Sciurus carolinensis) also produces banded hairs, having a white tip, a band of black and then an orange base. ${ }^{24}$ Melanism in the grey squirrel is associated with an eight amino acid deletion in the MC1R. ${ }^{24}$ The grey phenotype is homozygous for the wildtype $M C 1 R$ $w t E^{+}$allele and the jet black phenotype is homozygous for the $M C 1 R \Delta 24 E^{B}$ allele. Jet black squirrels have no agouti banding and produce only solid black hairs (supplementary material S1).

In this study we report how the MC1R of wildtype and melanic squirrels respond to $\alpha$ MSH and ASIP in transfected cell models. The results demonstrate that the eight amino acid deletion in the MC1R of the melanic grey squirrel leads to a constitutively active receptor. We also demonstrate that ASIP acts as an agonist instead of an inverse agonist to the MC1R $\Delta 24$ melanic variant and offer a working hypothesis as to how structural changes caused by this deletion may lead to the observed changes in activity. 


\section{Materials and Methods}

DNA constructs

Genomic DNA was extracted from muscle tissue of wildtype and jet black squirrels using a Qiagen blood and tissue kit following the manufacturer's instructions. The entire coding sequences of the wildtype $M C 1 R-w t E^{+}$(accession number EU604831.2) and mutant $M C 1 R \triangle 24 E^{B}$ (accession number EU604830.3) genes were amplified by PCR in a total volume of $25 \mu$ using approximately $25 \mathrm{ng}$ template DNA, $3 \mathrm{mM} \mathrm{MgCl} 2,0.2 \mathrm{mM}$ dNTPs, $0.4 \mu \mathrm{M}$ primers, and 0.1 $\mu 1$ Taq polymerase using the following PCR parameters: initial denaturation $94^{\circ} \mathrm{C}$ for $2 \mathrm{~min}$ followed by 35 cycles of $94^{\circ} \mathrm{C}$ for $30 \mathrm{~s}$, $68^{\circ} \mathrm{C}$ for $30 \mathrm{~s}$, and $72^{\circ} \mathrm{C}$ for $5 \mathrm{~min}$. The final extension step was performed at $72^{\circ} \mathrm{C}$ for $30 \mathrm{~min}$. The following primers were used (start codon underlined and stop codon removed in the position indicated by the vertical line) MC1Rexpf1 5'CACCATGGCTGTACAGAGGAGGCTCC -3', MC1Rexpr1 5'C | CCAGGAGCACAGCAGCACCTCC-3'. PCR products were cloned into a pcDNA3.1/CT-GFP-TOPO ${ }^{\circledR}$ Invitrogen expression vector such that the genes were tagged with GFP on the $\mathrm{C}$ terminus. Constructs were verified by complete sequencing.

Cell culture and transfection HEK293T cells were routinely maintained in DMEM Glutamax (Invitrogen) supplemented with $10 \%$ fetal bovine serum and $100 \mathrm{U} / \mathrm{ml}$ of penicillin and $100 \mu \mathrm{g} / \mathrm{ml}$ streptomycin sulphate in $5 \% \mathrm{CO}_{2}$ at $37^{\circ} \mathrm{C}$. Cells were seeded at $1 \times 10^{5}$ cells $/ \mathrm{ml}$ into 24 well plates, in the absence of antibiotic and grown for 24 hours until they were $80 \%$ confluent. Cells were then transiently transfected with expression vectors at 
$1 \mu \mathrm{g} / \mu 1$ using Fugene (Promega) following the manufacturer's instructions with $0.5 \mu \mathrm{g}$ DNA, $1.5 \mu$ l Fugene in $25 \mu 1$ opti-MEM ${ }^{\circledR}$ per well. Confocal visualisation and FACS confirmed transfection and protein expression 24 hours after transfection.

Functional assays

All experiments were carried out in triplicate and independent experiments were repeated three times. Media were removed from the wells and cells were washed with PBS. Varying concentrations of $\alpha$-MSH (Sigma) and ASIP (93-132-amide mouse, Phoenix peptides) were prepared in serum-free media. $400 \mu \mathrm{l}$ of serum-free media containing the relevant concentrations of $\alpha-\mathrm{MSH}$ and/or ASIP were added to each well and cells were incubated at $37^{\circ} \mathrm{C}$ for 45 minutes. Media were then removed and cells were washed carefully with PBS. Ice cold lysis buffer $(200 \mu 1)$ was added to each well and the cells were shaken in plates for 20 minutes on ice. The contents of each well were spun at $13000 \mathrm{rpm}$ for 10 minutes and cAMP was measured using a colorimetric ELISA from Cell Biolabs Inc. following the manufacturer's instructions. Results were normalised against total cellular protein content.

Computer modelling

Computer modelling of the MC1R variants was carried out using Phyre $^{2}$ and Wincoot. ${ }^{25,26}$ Docking of the MC1R receptor and ASIP used the Fast-Fourier shape and electrostatic method of Hex 6.3 followed by side-chain energy minimization and clustering of resulting complexes. ${ }^{27}$ Structural diagrams were prepared using Molsoft ICM browser (http://www.molsoft.com).

\section{Results}

Cells transfected with the MC1R-wt gene showed a basal level of activity producing $10 \%$ maximal cAMP (100\% maximal response being the production of 0.95 pmole 
cAMP per $\mu g$ protein in these experiments). The MC1R-wt cells showed a dose response to increasing concentrations of $\alpha-\mathrm{MSH}$. With increasing concentrations of $\alpha$ $\mathrm{MSH}$, in the presence of $10 \mu \mathrm{M}$ ASIP, the MC1R-wt cells showed a decrease in cAMP production even with the highest concentration of $\alpha-\mathrm{MSH}$ at $100 \mu \mathrm{M}$ (Fig. 1A). MC1R-wt cells showed a dose response to rising concentration of ASIP with decreasing levels of cAMP production (Fig. 1B). In contrast, the MC1R $\triangle 24$ transfected cells showed an elevated level of basal activity (30\% maximal), together with a dose response to $\alpha-\mathrm{MSH}$. The MC1R $\Delta 24$ cells showed an increased level of cAMP on stimulation with $10 \mu \mathrm{M}$ ASIP (70\% maximal) and cAMP production continued to rise with increasing levels of $\alpha-\mathrm{MSH}$ to the maximal response of $100 \%$ with cells producing 0.95 pmole cAMP per $\mu$ g protein (Fig. 1A). Contrary to expectations, MC1R $\Delta 24$ cells showed a dose response to increasing concentrations of ASIP with increasing cAMP production (Fig. 1B). These results show that $\alpha-\mathrm{MSH}$ is an agonist for both MC1R variants but that ASIP, whilst being an inverse agonist for MC1R-wt, is actually an agonist for MC1R $\Delta 24$. Furthermore, these results show that the MC1R $\Delta 24$ is constitutively active.

\section{Discussion}

During basal activity, GPCRs are in equilibrium between R (inactive) and R* (active) states. Agonists bind to the receptor and stabilise the $\mathrm{R}^{*}$ conformation leading to full activation of a signalling pathway whereas inverse agonists bind to the receptor and stabilise the R conformation which leads to a decrease in basal activity. Interestingly, it has been shown that inverse agonists are more stabilising whereas agonists induce more flexibility. ${ }^{28}$ In constitutively active receptors, the equilibrium between $\mathrm{R}$ and $\mathrm{R} *$ is moved so that receptors are more often in the $\mathrm{R}^{*}$ state..$^{29,30,31,32,33}$ Many mutations 
leading to constitutive activity disrupt non-covalent intramolecular interactions, altering the conformation and local dynamics and binding characteristics of ligandbinding pockets, and areas distal to such sites. It also seems likely that some mutations leading to constitutive activation mimic the active conformation stabilised by agonists of the wildtype receptor. However, it is also likely that there is more than one conformation that can activate a $\mathrm{G}$ protein. The receptor may have a new and completely different active conformation that binds to the intracellular effector in a different and possibly more effective way. ${ }^{34,35}$

MC1Rs have a ligand binding pocket located below the plasma membrane to which several transmembrane helices (TMs) contribute. ${ }^{36}$ There are three residues in particular, located deep in the pocket, which are important for ligand binding and which are highly conserved in all melanocortin receptors. These residues are E92, D117 and D121 (mouse numbering) and they contribute to a highly charged, acidic region involved in ligand binding. The MC1R agonist $\alpha-\mathrm{MSH}$ contains the highly conserved HFRW sequence. Truncation and mutational studies have shown this to be the minimal sequence required for binding and activation of the MC1R ${ }^{36}$ The His residue of this motif seems to be important for stabilising the ligand-receptor complex and its ring formation permits conformational change to take place which is required for signal transduction. The neighbouring Phe residue also contributes to a stable complex through a hydrophobic aromatic network at the ligand and receptor interface. The Arg residue is essential for activation and it is postulated that it interacts with E92, D117 and D121 acidic cluster on the receptor. The Arg also seems to be important for molecular recognition. ${ }^{37,38}$ 
Analysis of GPCR structures indicate that TM3 acts as an important structural and functional 'hub' through contact with four other helices. ${ }^{34,35}$ During activation, agonist binding generally induces a $2 \AA$ shift of TM3 towards the extracellular side of the receptor. This movement alters the position of the highly conserved DRY motif of TM3 which, after activation, interacts with the heterotrimeric G protein subunit on the cytosolic side of the receptor. ${ }^{39,40}$ It is predicted that ligand binding provokes this movement of TM3 and it is likely that any mutations which alter its interactions are likely to affect activity.

A number of mutations on the MC1R are associated with melanism, for example the E92K mutation found in mice, chicken, Japanese quail and the bananaquit. ${ }^{41,42,43,44}$ In both the mouse and chicken, this mutation is known to lead to a constitutively active receptor. ${ }^{41,45}$ Mutagenesis studies on the E92 position confirm that a change from an acidic to a basic amino acid, either Lys or Arg, leads to constitutive activity. Binding studies showed however that the E92K reduced ligand binding. ${ }^{21}$ It therefore seems likely that E92, D115 and D119 are in close proximity, but that they contribute to electrostatic repulsion between TM2 and TM3 (Fig. 2 and 3D and E). The introduction of a basic residue could reduce this repulsion and so alter the overall structure of the receptor, which might then lead to activation. Similarly, the C125R mutation associated with constitutive activation and melanism in the fox would introduce a positive charge and is likely to have a similar agonist mimicking effect. ${ }^{46}$ The L98P and L99P mutations associated with constitutive activity and melanism in mice and pigs, which introduce a Pro, would likely modify the TM positions and again the effect would be transmitted along the TM3. ${ }^{41,47}$ Thus, it seems likely that the effect of the E92K, C125R, L98P and L99P mutations are mimicking the action of the 
Arg residue of $\alpha-\mathrm{MSH}^{21}$ Studies on the E92K mutation showed that the active conformation induced by ligand binding is distinct from that induced by the mutation and that the extracellular loop one (ECL1) was involved with maintaining the active conformation. ${ }^{48}$ The effects of these mutations may transmit a conformational change along the TM2/TM3 bundle and ultimately can be envisaged to transmit a structural signal to the intracellular side of the receptor and in this way affect $G$ protein specificity, turnover and/or binding energies. ${ }^{21}$

MC1Rs are unusual in having both endogenous agonist and inverse agonists. ASIP, which normally functions as an inverse agonist, is much larger and structurally very different to $\alpha-\mathrm{MSH}$. Three functional domains have been identified in ASIP: the Cterminal loop, the active loop and the $\mathrm{N}$-terminal loop. The active loop contains the highly conserved RFF motif which is essential in recognition, binding and inverse agonist function and makes direct contact with the receptor in the transmembrane pocket. ${ }^{49,50,51}$ The site of contact is thought to be partially overlapping the site for $\alpha$ MSH. ${ }^{52,53}$ The action of RFF is thought to mimic the action of the HFRW sequence of $\alpha-\mathrm{MSH}$. Interestingly, the partial sequence of ASIP, CRFFNAFC, functions not as an inverse agonist, but as an agonist. ${ }^{54}$ Similar short peptides are also agonists to MC4R. ${ }^{55}$ All three loops of ASIP are required for full function as an inverse agonist, but studies have shown that chimeras lacking the C-terminal loop have reduced binding affinities and most remarkably functioned as agonists. ${ }^{56}$ This suggests that the C-terminal loop is essential for function as an inverse agonist. It has been shown that the C-terminal loop forms a contact point with ECL1 of the MC1R (Fig. 3). Specifically, the LVARAA sequence of human MC1R and VLSLN of ASIP form hydrophobic interactions. ${ }^{56}$ It has been suggested that with no stabilisation from 
interactions of the C-terminal loop, the RFF active domain relocates to the same position as the HFRW motif and thus activates the receptor in a similar way to $\alpha$ $\mathrm{MSH}^{52}$ This relocation may be occurring on the MC1R $\Delta 24$ as depicted in figure 4.

Computer modelling by Phyre $^{2}$ matches the squirrel MC1R sequence to the adenosine a2a receptor (PDB id: $3 \mathrm{EML}$ ) with $85 \%$ coverage and produces a structural model at high confidence level. This model predicts that the SNALETTI sequence in the MC1R-wt is in TM2 and predicts that deletion of SNALETTI from MC1R $\Delta 24$ causes the FLLLEVGALA sequence from wildtype ECL1 to be incorporated into TM2 leading to a truncated ECL1 in the mutant (Fig. 2). Given the finding that ECL1 is vital for the ASIP to act as an inverse agonist and that ASIP with no C-terminus loop acts as an agonist, it seems likely that the shorter ECL1 of MC1R $\Delta 24$ is preventing ASIP from inactivating the receptor and instead the ASIP is able to bind to the same region as the $\alpha-\mathrm{MSH}$ and activate the receptor (Figs. 3 and 4). Interestingly, the melanic jaguar and melanic jaguarundis both have deletions in this region of the MC1R (Table 1). ${ }^{57}$ Although these deletions fall in slightly different regions, computer models predict that the effects on ECL1 are similar (Fig. 5). Indeed in all three species, ECL1 contains a section of $\beta$-strand and hydrophobic residues important for inverse agonist activity in the wildtype. Figure 5 shows clearly that all ECL1s are shortened in the melanic phenotypes with no $\beta$-strand and fewer hydrophobic residues. It seems likely that these deletions are having similar effects to those found in the squirrel, causing changes to agonist and inverse agonist activity and causing constitutively active receptors. 
There are a number of ways the eight amino acids deleted in the MC1R $\Delta 24$ could be altering the function of the receptor. Firstly, the wildtype and mutant TM2s now differ substantially and it seems likely that there will be different packing of TM2 and TM3 between the two cases. It may be hypothesised that TM2 differences and ECL1 shortening could lead to an upward shift of the TM2-TM3 bundle towards the extracellular side thus mimicking the effect of agonist binding, creating the upward movement observed in active receptors. Secondly, the E91 of the squirrel MC1R-wt (E92 equivalent) is deleted which may, as previously noted, be involved in repulsion between TM2 and TM3 in the wildtype. With this repulsion removed, TM2 and TM3 could be more closely associated. Interestingly, however, models predict an $\mathrm{E}$ in position 91 in both cases where E99 is relocated into the pocket in the MC1R $\Delta 24$ (Fig. 2 and 3D and E). This replacement could account for the MC1R $\Delta 24$ still being responsive to $\alpha-\mathrm{MSH}$. It is likely that the E91 will be differently positioned in each case which could alter basal activity and could also contribute to an altered interaction with ASIP. Thirdly, with fewer amino acids to contribute to stability and an altered arrangement, the MC1R $\Delta 24$ receptor may be more flexible than its wildtype counterpart and more likely to be in the $\mathrm{R}^{*}$ state. Indeed, models predict that N88 of SNALETTI forms a hydrogen bond with $\mathrm{S} 124$ which is absent in MC1R $\Delta 24$. This would be consistent with the finding that the MC1R $\Delta 24$ is constitutively active but also still responsive to ligands, possibly interacting normally with the remaining unaffected loops. Fourthly, the deleted amino acids may have the opposite effect, creating a more stable receptor with an altered architecture and a permanently enlarged binding region for the $\mathrm{G}$ protein so that it is more often in the $\mathrm{R}^{*}$ state. 
These experiments in transfected cells with ASIP [93-132] show that the MC1R-wt behaves as a carefully balanced switch capable of activation by $\alpha-\mathrm{MSH}$ and inactivation by ASIP. In contrast, the MC1R $\Delta 24$ has lost the ability to act as an effective switch and is constantly activated, having no "off switch". These results suggest that the MC1Rs of the melanic and wildtype squirrel may behave in the same way in vivo. In native tissue however, there may be differences in $\mathrm{G}$ protein to receptor coupling, squirrel ASIP may behave differently to ASIP [93-132] and the presence of endogenous $\alpha-\mathrm{MSH}$ should be considered. These results predict that the MC1R-wt in melanocytes would respond to $\alpha-\mathrm{MSH}$ and ASIP producing varying levels of intracellular cAMP, ultimately leading to the production of banded phaeomelanin/eumelanin hairs of the wildtype grey squirrel. In contrast, melanocytes with MC1R $\Delta 24$ may only be capable of producing eumelanin leading to the production of unbanded jet black hairs of the melanic grey squirrel. Further studies on squirrel melanocytes and in vivo studies would be needed to confirm these predictions.

We conclude that the eight amino acid deletion of the MC1R $\Delta 24$ leads to a constitutively active receptor, producing a higher basal level of intracellular cAMP compared to the MC1R-wt and that ASIP acts as an inverse agonist to MC1R-wt but as agonist to MC1R24. This study is the first to date to report that ASIP acts as an agonist to the MC1R in any species. 

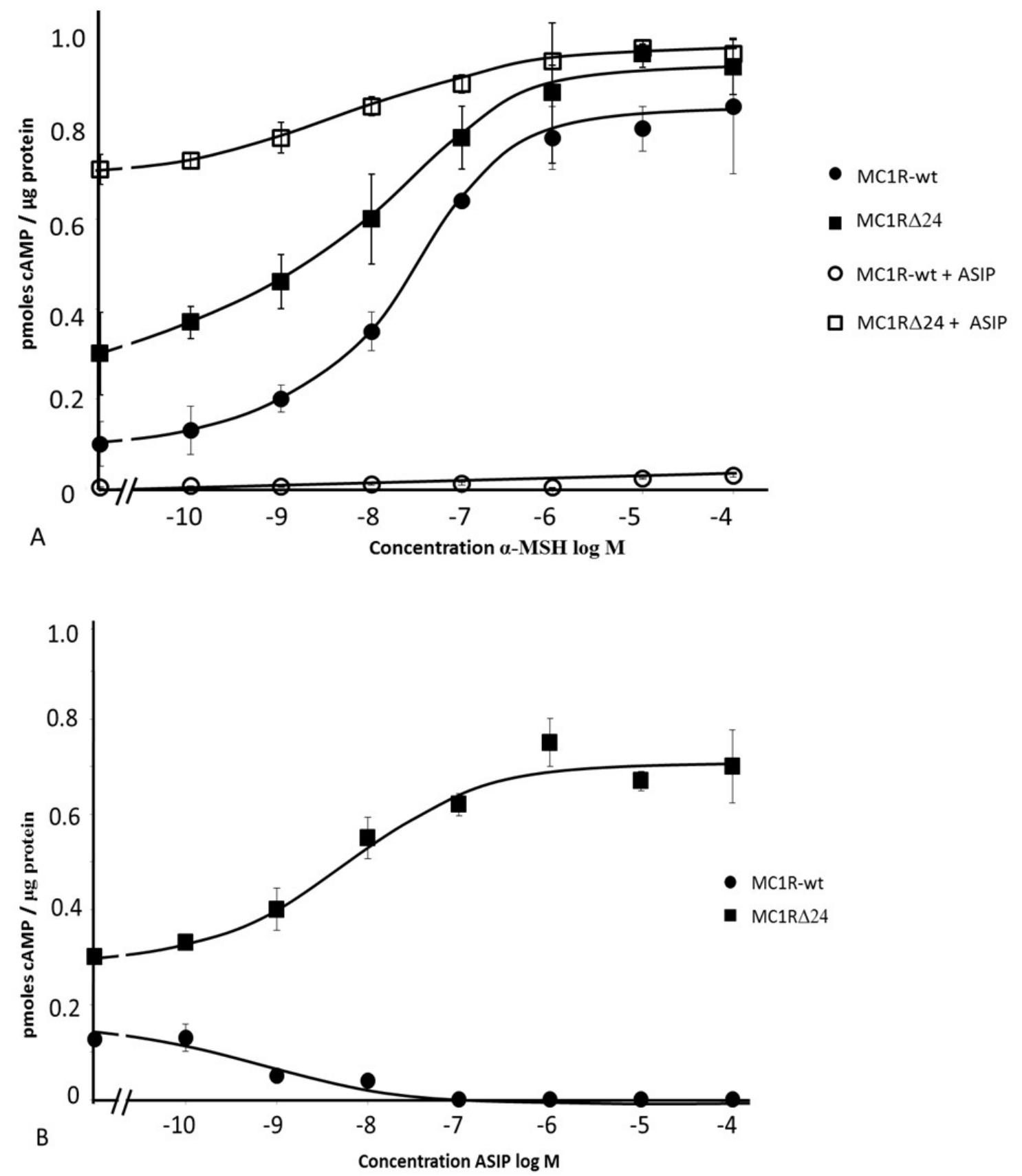

Figure 1 Functional coupling of MC1R-wt and MC1RA24 with a-MSH and ASIP. (A) Changes to intracellular levels of cAMP in response to a-MSH in MC1R-wt and MC1RA24 transfected into HEK293T cells with and without 10,000nM ASIP. (B) Changes to intracellular levels of cAMP in response to ASIP in MC1R-wt and MC1RA24. Values on the $y$ axis represent basal levels of activity in the absence of ligand. Data points show means of triplicates of typical dose response curve determination experiments. Error bars indicate standard error of the mean. 


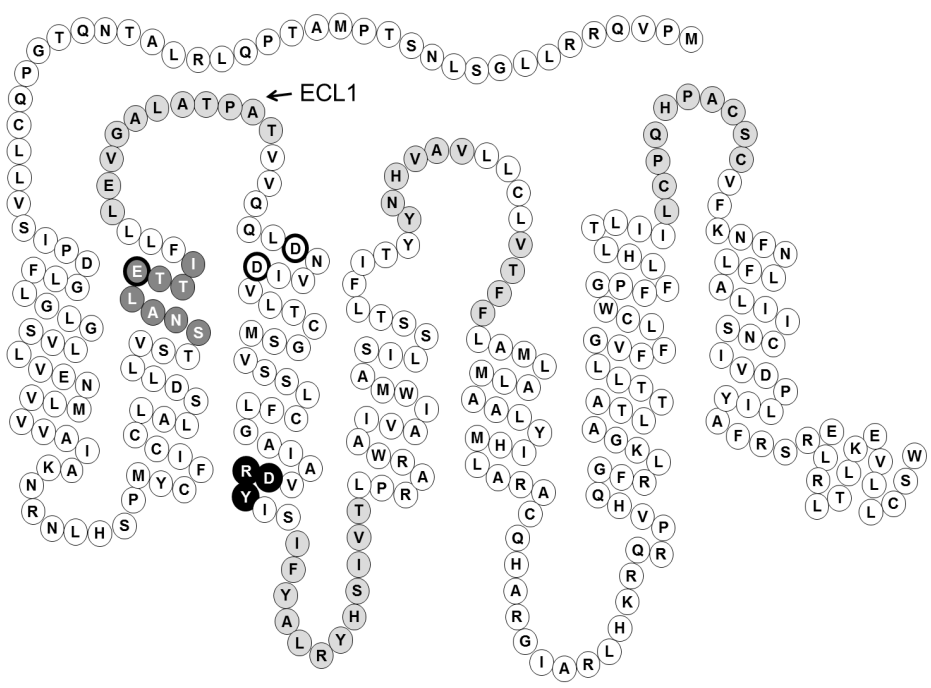

A

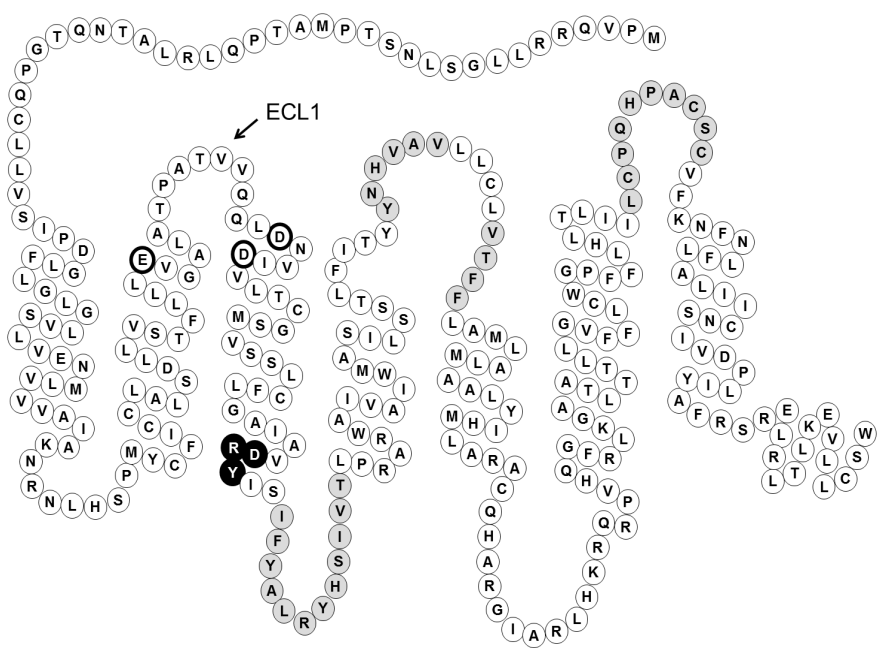

B

Figure 2 Schematic representations of MC1R-wt and MC1RA24 based on Phyre² and Hex6.12 computer programmes. Amino acid residues that form $\beta$-strands are shown as light grey circles. (A) Predicted structure of the MC1R-wt showing the eight amino acids (SNALETTI) deleted in the MC1RA24 as dark grey circles with white lettering. E91, D124 and D128, thought to be important in ligand binding are highlighted with bold outline. The highly conserved DRY motif of TM3 is shown as black circles with white lettering. (B) Predicted structure of the MC1RA24 showing a shortened extracellular loop 1 (ECL1) compared with the wildtype receptor. The E91 highlighted with bold outline is the E99 of the wildtype relocated to the helix. 

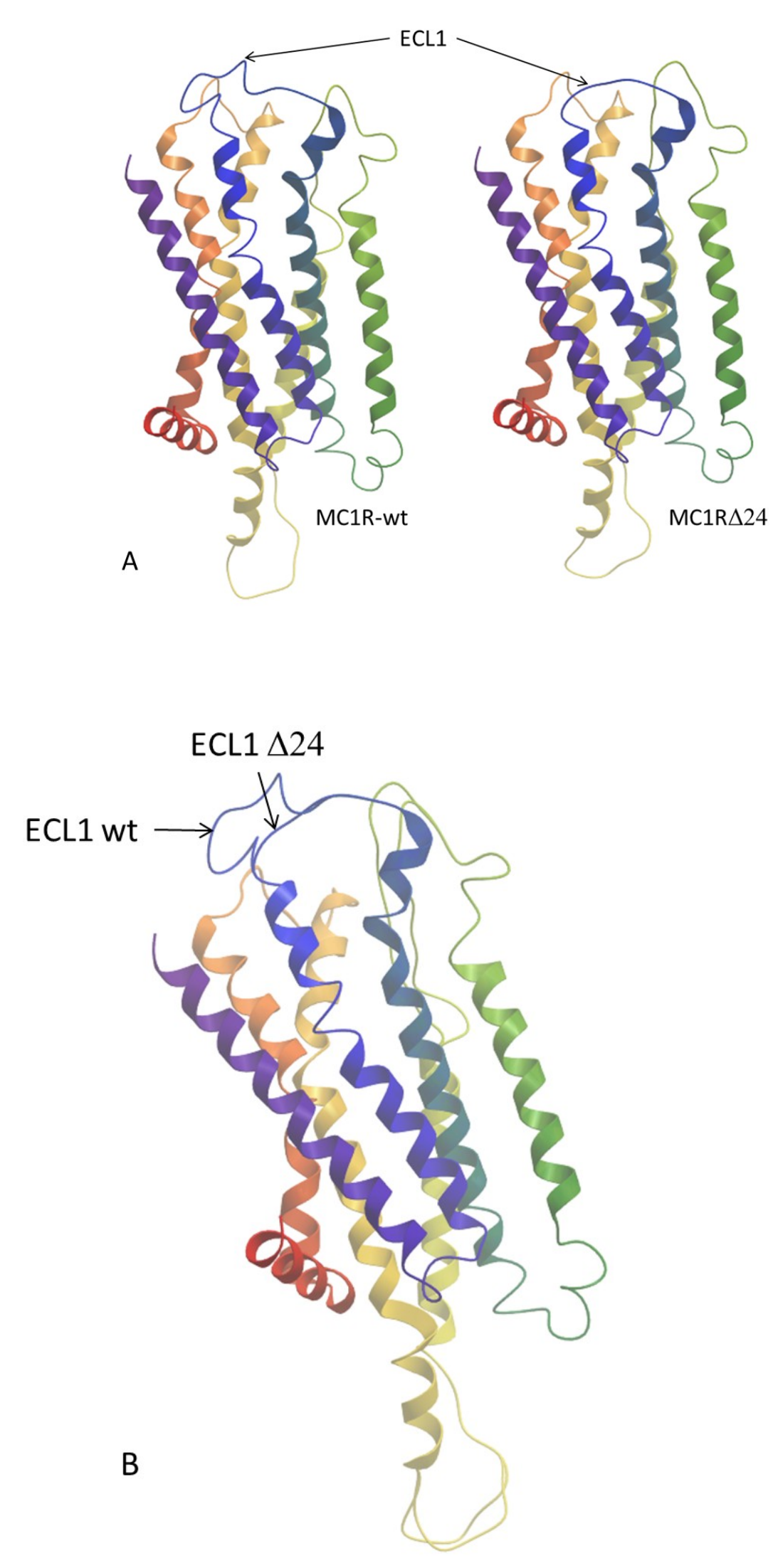

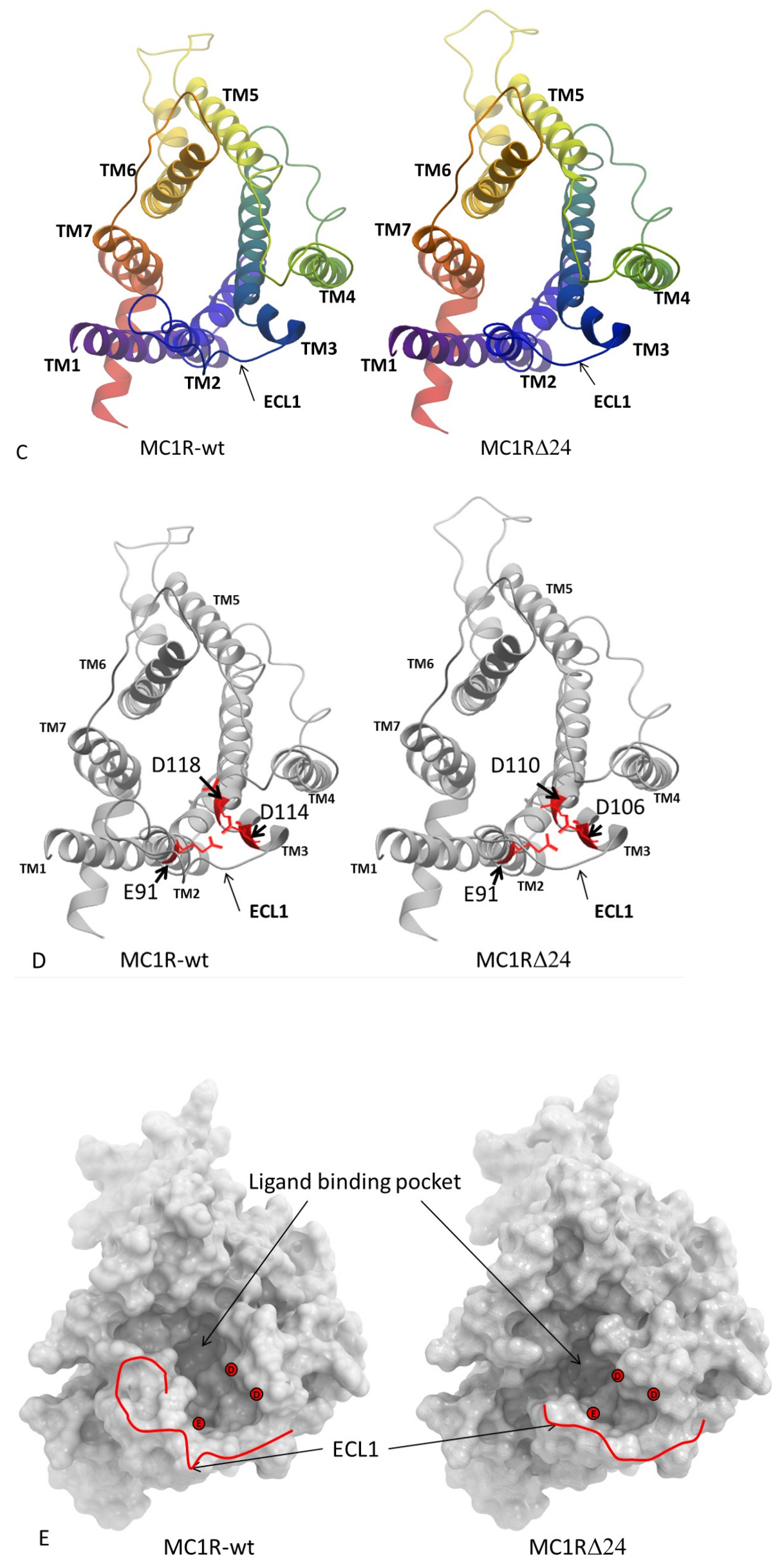


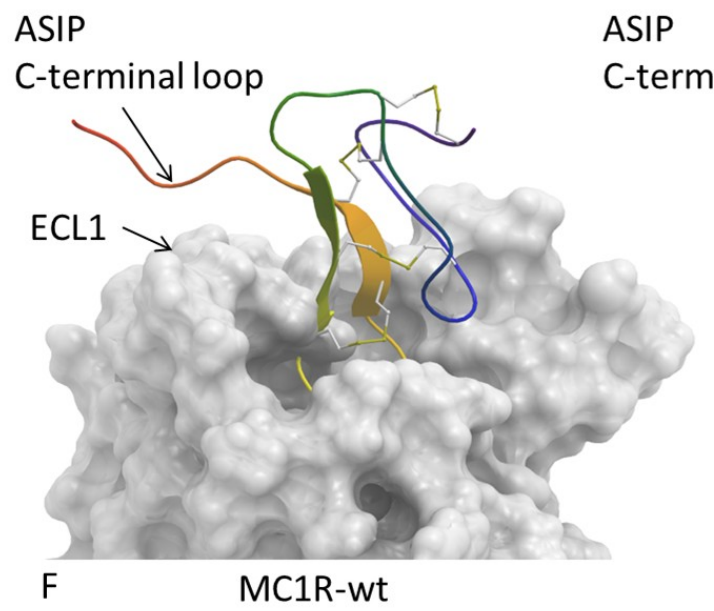

ASIP

C-terminal loop
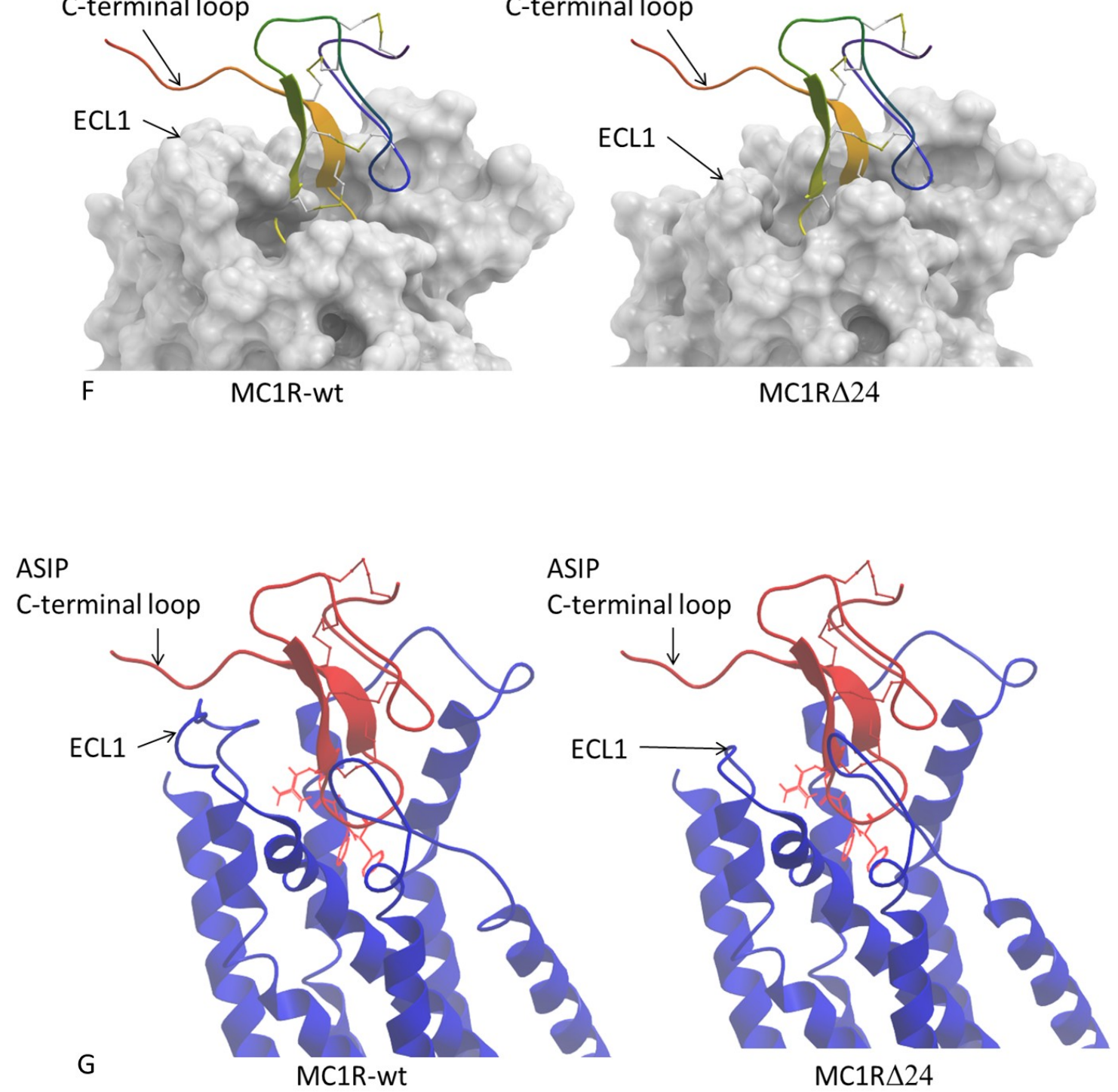

Figure 3 Computer models of MC1R-wt and MC1RA24. (A) Side view of the MC1R-wt and MC1RA24. (B) MC1R-wt and MC1RA24 superimposed on each other. (C) Extracellular view of the predicted binding pocket showing TMs. (D) Extracellular view of the predicted binding pockets with E91, D114, D118 and melanic equivalents highlighted. (E) Extracellular view of binding pockets with Connolly surface shown. (F and G) MC1R-wt and MC1RA24 with ASIP, showing ASIP C-terminal loop and MC1R ECL1. G also shows the RFF motif in the active loop of ASIP as wire representation. 


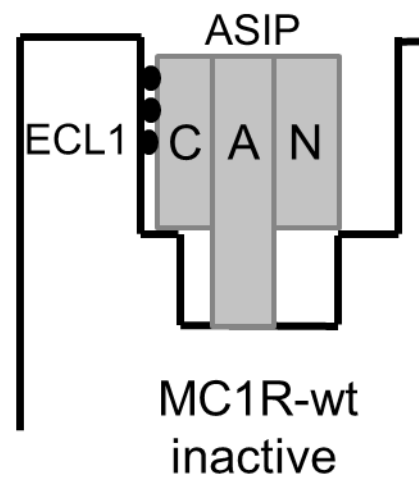

A

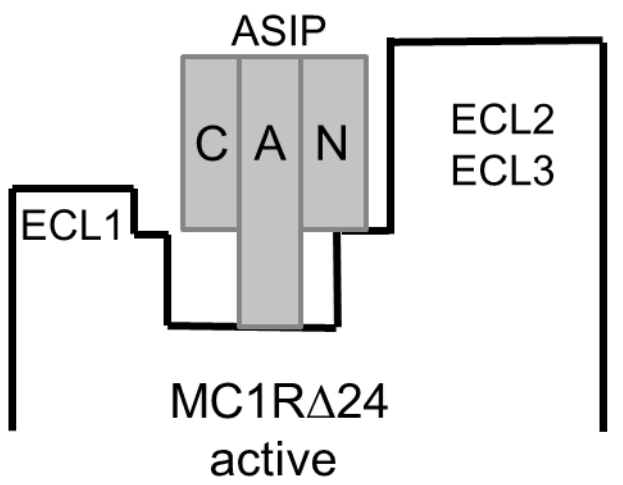

B

Figure 4 Schematic representation of ASIP-MC1R-wt and ASIP-MC1RA24 interactions. C=Cterminal loop, $A=$ Active loop and $N=N$-terminal loop of ASIP. (A) Predicted hydrophobic interactions between the C-terminal loop of ASIP and ECL1 of MC1R-wt are shown as black circles. (B) Predicted relocation of ASIP when interacting with MC1RA24 leading to activation of the receptor adapted from Patel et al (2010).

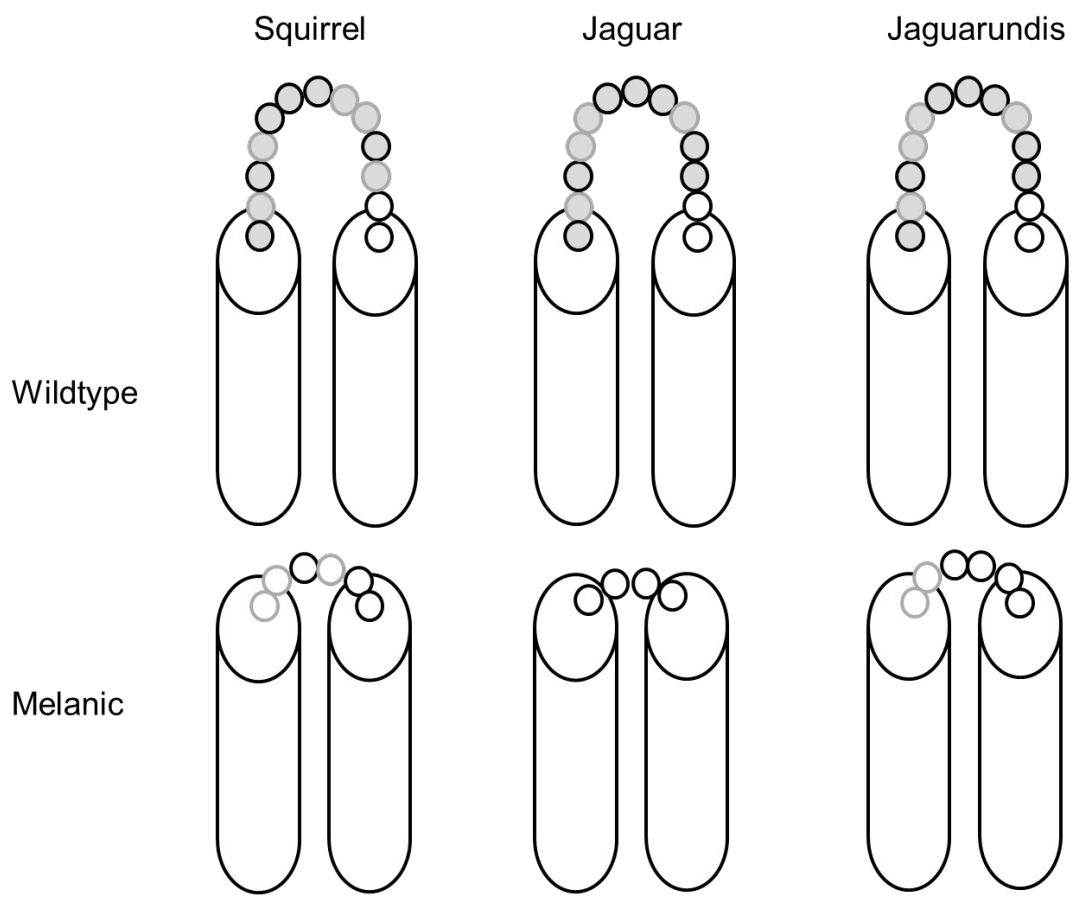


Figure 5 Schematic representation of TM2, TM3 and ECL1 from the MC1R of wildtype and melanic squirrel, jaguar and jaguarundis. Amino acids that form part of $\beta$-pleated sheets are shown as grey circles. Hydrophobic amino acids are shown as circles with black outlines.
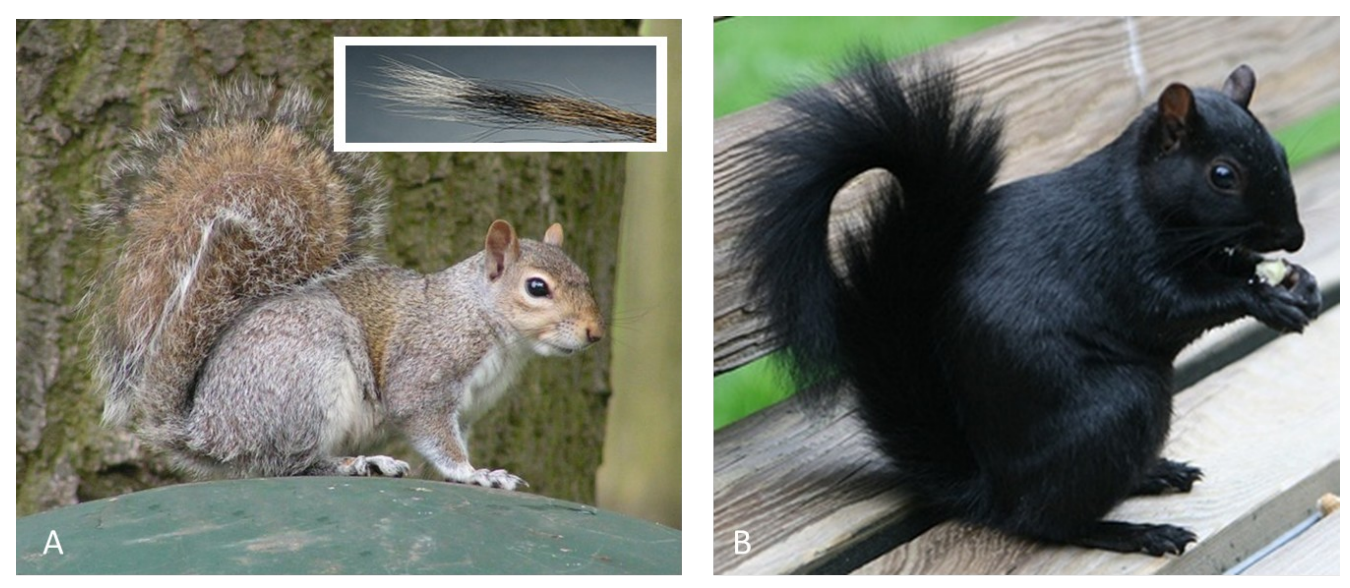

Supplementary material S1 (A) Wildtype $S$. carolinensis showing banded hairs in the inset. (B) Jet black $S$. carolinensis.

\section{Acknowledgements}

We would like to thank Mark D'Arcy and Dan Rewcastle for helpful technical support.

This work was funded by Anglia Ruskin University. Work was carried out in accordance with all relevant ethical codes of practice. There are no conflicts of interest. 


\section{References}

1 Barrowclough G, Sibley F. 1980. Feather pigmentation and abrasion: test of a hypothesis. Auk. 97:881-883.

2 Burtt E. 1986. An analysis of physical, physiological and optical aspects of avian coloration with emphasis on wood-warblers. Ornithol. Monogr. 38: 1-126.

3 Goldstein G, Flory K, Browne B, Majid S, Ichida JM, Burtt JEH.2004. Bacterial degradation of black and white feathers. Auk. 121: 656-659.

4 Bokony V, Liker A, Székely T, Kis J. 2003. Melanin-based plumage coloration and flight displays in plovers and allies. Proc. Roy. Soc. B. 270: 2491-2497.

5 Jawor J, Breitwisch R. 2003. Melanin in ornaments, honesty, and sexual selection. Auk. 120: 249-265.

6 Roulin A. 2004. The evolution, maintenance and adaptive function of genetic colour polymorphism in birds. Biol. Rev. 79: 815-848.

7 Mundy NI. 2005. A Window on the genetics of evolution: MC1R and plumage colouration in birds. Proc. Roy-Soc. B. 272: 1633-1640.

8 Hearing VJ, Tsukamoto K. 1991. Enzymatic control of pigmentation in mammals. FASEB. 5: 2902-2909.

9 Sanchez-Mas J, Hahmann C, Gerritsen I, Garcia-Borron JC, Jimenez-Cervantes C. 2004. Agonist-independent, high constitutive activity of the human melanocortin 1 receptor. Pigment Cell Res. 17: 386-395.

10 Mountjoy KG, Robbins LS, Mortrud MT, Cone RD. 1992. The cloning of a family of

genes that encode the melanocortin receptors. Science. 254: 1248-1251.

11 Donatien PD, Hunt G, Pieron C, Lunec J, Taieb A, Thoday AJ. 1992. The expression of functional MSH receptors on cultured human melanocytes. Arch. Dermatol. Res

284: 424-426.

12 Chakraborty AK, Funasaka Y, Slominski A, Ermak G, Hwang J, Pawelek JM, Ichihashi M. 1996. Production and release of proopiomelanocortin (POMC) derived pepides by human melanocytes and keratinocytes in culture: regulation by ultraviolet B. Biochim. Biophys. Acta 1313: 130-138.

13 Cone RD, Mountjoy KG, Robbins LS, Nadeau JH, Johnson KR, Roselli-Rehfuss L, Mortrud MT. 1993. Cloning and functional characterization of a family of receptors for the melanotropic peptides. Ann. N. Y. Acad. Sci. 680: 342-363. 
14 Garcia-Borron JC, Sanchez-Laorden BL, Jimenez-Cervantes C. 2005.

Melanocortin-1 receptor structure and functional regulation. Pigment Cell Res. 18: 393-410.

15 Roesler WJ, Park EA, McFie PJ. 1998. Characterisation of CCAAT/enhancerbinding protein alpha as a cyclic AMP-responsive nuclear regulator. J Biol Chem. 273:14950-14957.

16 Slominski A, Plonka PM, Pisarchik A, Smart JL, Tolle V, Wortsman J, Low MJ. 2005. Preservation of eumelanin hair pigmentation in proopiomelanocortin-deficient mice on a nonagouti (a/a) genetic background. Endocrinology 146: 1245-1253.

17 Abdel-Malek ZA, Swope V, Suzuki I, Akcali C, Harriger M, Boyce S, Urabe K, Hearing VJ. 1995. Mitogenic and melanogenic stimulation of normal human melanocytes by melanotropic peptides. Proc Natl Acad Sci USA 92:1789-1793.

18 Bertolotto C, Abbe P, Hemesath TJ, Bill, K, Fisher DE, Ortonne JP, Ballotti R. 1998. Microphthalmia gene product as a signal transducer in cAMP-induced differentiation of melanocytes. J. Cell Biol. 142: 827-835.

19 Rouzaud F, Annereau JP, Valencia JC, Costin GE, Hearing VJ. 2003. Regulation of melanocortin 1 receptor expression at the mRNA and protein levels by its natural agonist and antagonist. FASEB J. 17: 2154-2156.

20 Bultman S J. 1992. Molecular characterisation of the mouse agouti locus Cell. 71: 1195-1204.

21 Lu D, Vage DI, Cone R. 1998. A ligand-mimetic model for constitutive activation of the melanocortin-1 receptor. Mol Endocrinol. 12: 592-604.

22 Barsh GS. 1996. Genetics of pigmentation: From fancy mice to complex traits. Trends Genet. 12: 299-305.

23 Abdel-Malek ZA, Scott MC, Furumura M, Lamoreux ML, Ollmann M,Barsh GS, Hearing VJ. 2001. The melanocortin 1 receptor is the principal mediator of the effects of agouti signalling protein on mammalian melanocytes. J Cell

Sci. 114:1019-1024.

24 McRobie HR, Thomas APM, Kelly J. 2009. The genetic basis of melanism in the gray squirrel (Sciurus carolinesis). Journal of Heredity. 100: 709-714.

25 Kelley LA, Sternberg MJE. 2009. Protein structure prediction on the web: a case study using the Phyre server. Nature Protocols 4: 363-371

26 Emsley P,Lohkamp B, Scott WG,Cowtan K. 2010. Features and Development of Coot. Acta Crystallographica Section D - Biological Crystallography. 66: 486-501

27 Ritchie DW and Kemp GJL. 2000. Protein Docking Using Spherical Polar Fourier Correlations. Proteins: Struct. Funct. Genet. 39, 178-194.) 
28 West GM, Chien EYT, PR. 2011. Ligand-dependent perturbation of the conformational ensemble for the GPCR $\beta 2$ adrenergic receptor revealed by HDX. Structure 19: 1424-1432

29 Chidiac P, Hebert TE, Valiquette M, Dennis M, Bouvier M. 1994. Inverse agonist activity of $\beta$-adrenergic antagonists. Mol Pharmacol 45: 490-499.

30 Samama P, Cotecchia S, Costa T, Lefkowitz R. 1993. Mutation- induced activated state of the $\beta 2$-adrenergic receptor. Extending the ternary complex model. J. Biol. Chem. 268: 4625-4636.

31 Samama P, Pei G, Costa T, Cotecchia S 1991. Negative antagonists promote an inactive conformation of the $\beta(2)$-adrenergic receptor. Mol Pharmacol. 45: 390-394.

32 Vaidehi N. Kenakin T. 2010. The role of conformational ensembles of seven transmembrane receptors in functional selectivity. Curr. Opin. Pharmacol. 10: $775-781$.

33 Provasi, D, Artach, MC, Negri A, Mobarec J C, Filizola M. 2011. Ligand-induced modulation of the free-energy landscape of $\mathrm{G}$ protein-coupled receptors explored by adaptive biasing techniques. PLoS Comput. Biol. 7, e1002193.

34 Venkatakrishnan AJ, Deup X, Lebon G, Tate CG, Schertler GF, Madan Babu M. 2013. Molecular signatures of G-protein-coupled receptors. Nature. 494: 185-194.

35 Schartz TW, Rosenkilde MM 1996 Is there a "lock" for all agonist "keys" in 7TM receptors? Trends Pharmcol Sci. 17: 213-216.

36 Haskell-Luevano C, Tomi C, Sawyer K, Siska Hendrata S, North C, Panahinia L, Stum M, Staples DJ, De Lauro Castrucci AM, Hadley ME, Hruby VJ. 1996.

Truncation studies of $\alpha$-melanotropin peptides identify tripeptide analogues exhibiting prolonged agonist bioactivity. Peptides. 17: 995-1002.

37 Yang YK, Dickinson CJ, Haskell-Luevano C, Gantz I. 1997. Molecular basis for the interaction of [Nle4,D-Phe7] melanocyte stimulating hormone with the melanocortin-1 receptor. J.Biol Chem. 272: 23000-23010.

38 Yang YK, Dickinson C J, Zeng Q, Li JY, Thompson DA, Gantz I. 1999. Contribution of melanocortin receptor exoloops to Agouti-related protein binding. J. Biol. Chem. 274: 14100-14106.

39 Lebon GT, Warne T, Tate GC. 2011. Agonist-bound adenosine A2A receptor structures reveal common features of GPCR activation. Nature. 474: 521-525.

40 Probst WC, Snyder LA, Schuster DI, Brosius J, Sealfon SC. 1992. Sequence alignment of the G-protein coupled receptor superfamily. DNA Cell Biol. 11: 1-20.

41 Robbins LS, Nadeau JH, Johnson KR, Kelly MA, Roselli-Rehfuss L, Baack 
E, Mountjoy KG, Cone RD. 1993. Pigmentation phenotypes of variant extension locus alleles result from point mutations that alter $\mathrm{MSH}$ receptor function.

Cell. 72: 827-834.

42 Takeuchi S, Suzuki H, Hirose S, Yabuuchi M, Sato C, Yamamoto H, Takahashi S. 1996. Molecular cloning and sequence analysis of the chick melanocortin 1 receptor gene. Biochim Biophys Acta. 1306: 122-126.

43 Nadeau NJ, Minvielle F, Mundy NI. 2006. Association of a Glu92Lys substitution in MC1R with extended brown in Japanese quail (Coturnix japonica). Animal Genetics. 37: 287-289.

44 Theron E, Hawkins K, Bermingham E, Ricklefs RE, Mundy NI. 2001. The molecular basis of avian plumage polymorphism in the wild: a melanocortin-1receptor point mutation is perfectly associated with the melanic plumage morph of the Bananaquit (Coereba flaveola). Curr Biol. 11:550-557.

45 Ling MK, Lagerstrom MC, Fredriksson R, Okimoto R, Mundy NI, Takeuchi S, Schioth HB. 2003. Association of feather colour with constitutively active melanocortin 1 receptors in chicken. Eur J Biochem. 270: 1441-1449.

46 Vage DI, Lu D, Klungland H, Lien S, Adalsteinsson S, Cone R.D. 1997. A non-epistatic interaction of agouti and extension in the fox, Vulpes vulpes. Nat Genet. 15: $311-315$.

47 Kijas JMH, Wlaes R, Tornsten A, Chardon P, Moller M, Andersson L. 1998. Melanocortin receptor 1 (MC1R) mutations and coat colour in pigs. Genetics. 150: 1177-1185.

48 Benned-Jenson T, Mokrosinski J, Rosenkilde MM. 2011. The E92K Melanocortin 1 receptor mutant induces cAMP production and arrestin recruitment but not ERK activity indicating biased constitutive signaling. PLoS-ONE. 6: e24644.

49 Tota MR, Smith TS, Mao C, MacNeil T, Mosley RT, Van der Ploeg LHT, Fong TM. 1999. Molecular interaction of Agouti protein and Agouti related protein with human melanocortin receptors. Biochemistry. 38: 897-904.

50 McNulty JC, Jackson PJ, Thompson DA, Chai B, Gantz I, Barsh GS, Dawson PE, Millhauser GL. 2005. Structures of the Agouti Signalling Protein. J Mol Biol. 346: 1059-1070.

51 Chai BX, Pogozheva ID, Lai, YM, Li JY, Neubig RR, Mosberg HI, Gantz I. 2005. Receptor- antagonist interactions in the complexes of agouti and agouti-related protein with human melanocortin 1 and 4 receptors. Biochemistry. 44:3418-3431.

52 Jackson P J, Yu B, Hunrichs B, Thompson D A, Chai B X, Gantz I, Millhause GL. 2005. Chimeras of the agouti-related protein: insights into agonist and antagonist selectivity of melanocortin receptors. Peptides. 26: 1978-1987. 
53 Haskell-Luevano C, Cone RD, Monck EK, Wan YP. 2001. Structural activity studies of the melanocortin-4 receptor by in vitro mutagenesis: identification of agouti-related protein (AGRP), melanocortin agonist and synthetic peptide antagonist interaction determinants. Biochemistry. 40: 6164-6179.

54 Haskell-Luevano C, Monck EK, Wan Y P, Schentrup AM. 2000. The agoutirelated protein decapeptide (Yc[CRFFNAFC]Y) possesses agonist activity at the murine melanocortin-1 receptor. Peptides. 21: 683-689.

55 Chai BX, Neubig RR, Millhauser GL, Thompson DA, Jackson PJ, Barsh GS, Dickinson CJ, Li JY, Lai YM, Gantz I. 2003. Inverse agonist activity of agouti and agouti-related protein. Peptides. 24: 603-609.

56 Patel MP, Camila S, Fabersunne C, Yang Y, Kaelin CB, Barsh GS, Millhauser GL. 2010. Loop-swapped chimeras of the agouti-related protein and the agouti signaling protein identify contacts required for melanocortin 1 receptor selectivity and antagonism. J Mol Biol 404: 45-55.

57 Eizirik E, Yuhki N, Johnson WE, Menotii-Raymond M, Hannah SS, O'Brien SJ. 2003. Molecular genetics and evolution of melanism in the cat family. Current Biology. 13: 448-453. 